\title{
The genetics of incompatibility in Sinapis arvensis L.
}

\author{
M. A. Ford and Q. O. N. Kay
}

Department of Botany and Microbiology, University College of Swansea, Swansea SA2 8PP, Wales.

\begin{abstract}
The incompatibility system of Sinapis arvensis $L$. was studied in a wild population from farmland in the Gower Peninsula, South Wales, using the pollen-stigma surface reaction as a measure of the compatibility or otherwise of a cross. No self-compatibility was found. The results obtained are consistent with the hypothesis that $S$. arvensis has a single-locus, multiallelic sporophytic incompatibility system similar to that found in other crucifers. Both dominance and independent action of alleles occurred in the pollen and stigma. Fourteen different $\mathrm{S}$-alleles were found in a sample of ten plants collected from a single field, indicating the occurrence of a minimum number of $24 \mathrm{~S}$-alleles in the population.
\end{abstract}

\section{INTRODUCTION}

Since Bateman (1955) first demonstrated that a single-locus sporophytic system was likely to be universal in the Brassicaceae (Cruciferae) the genetic control of incompatibility has been investigated in several more species in the family. Among these, Brassica oleracea (Sampson, 1957), Lesquerella densipila (Sampson, 1958), Raphanus raphanistrum (Sampson, 1964), and Leavenworthia crassa (Lloyd, 1967) were shown to have the expected single-locus sporophytic system, although a sporophytic system controlled by more than one locus was reported to occur in Eruca sativa by Verma, Malik and Dhir (1977).

The general biology of Sinapis arvensis was studied by Fogg (1950) who assumed that the species was self-compatible, apparently without investigating the point. However, Bateman (1955), in a general survey of breeding systems in the Brassicaceae, listed two un-named species of Sinapis as self-incompatible on the basis of the difference in seed-set following manual self- and cross-pollination. Sinapis arvensis and $S$. alba are the only common species in the genus and these are likely to have been the species that were tested by Bateman. Mulligan and Bailey (1975), in an account of the biology of $S$. arvensis in Canada, stated that it is self-incompatible.

Most investigations of self-incompatibility in crucifers have either been limited to demonstration of the occurrence of the expected single-locus sporophytic system in the species under study (e.g.,
Sampson, 1964) or have involved the dominance relationships between alleles in cultivated species (e.g., Thompson and Taylor, 1966). Only one study, that of Raphanus raphanistrum by Sampson (1967), has been directed towards obtaining an estimate of the number of S-alleles occurring in a noncultivated crucifer. Although the numbers of Salleles that occur in wild species with single-locus gametophytic systems have now been studied in a few cases (e.g., Oenothera organensis, Emerson, 1939; Papaver rhoeas, Campbell and Lawrence, $1981 a, b)$ Sampson's study of Raphanus raphanistrum still appears to be the only attempt to estimate the total number of S-alleles occurring in a wild species with a single-locus sporophytic system. We hope that the present paper will be the first of a series describing the results of an extensive survey of the S-alleles occurring in wild populations of Sinapis arvensis.

\section{MATERIALS AND METHODS}

The methods follow those used by Mackay (1977) and described in detail by Wallace (1979). The compatibility of all crosses was assessed solely by pollen tube penetration, a more reliable technique than seed counting (van Hal and Verhoeven, 1968). In some cases seed-set may follow incompatible crosses because a few pollen-tubes may penetrate and effect fertilisation, while seed-set may fail after a compatible cross because of abortion of the zygotes, particularly in inbred lines. 
Fifty well-grown plants of $S$. arvensis in flower were collected from a cultivated field near Llanrhidian, in the Gower Peninsula, S. Wales (G.R. SS 474.925) in October 1981. The minimum distance between the plants that were collected was three metres. These plants (the $\mathrm{I}_{0}$, non-inbred, generation) were grown on in $15 \mathrm{~cm}$ pots in a cool greenhouse with additional lighting. Under these conditions some plants continued to flower until the spring of 1982. The healthy flowering plants were bud-selfed during the winter to produce inbred seed.

The first inbred generation (the $I_{1}$ generation) was raised in the same greenhouse during the following winter. 20 families were raised, with from 4 to 15 plants in each progeny, depending on the amount of selfed seed obtained from the parent and the survival of the seedlings. Reciprocal intercrosses were made within each progeny to identify the plants that were homozygous for different Salleles. In a number of small progenies all crosses proved to be reciprocally incompatible, and, in the absence of the recessive homozygote, S-allele genotypes could not be assigned to any of the plants. In ten progenies both homozygotes were recognized. These were assigned provisional $S$ allele numbers from $S_{1}$ to $S_{20}$, and were bud-selfed and crossed to produce seed for the $I_{2}$ (second inbred) generation. A few inter-progeny crosses were made between homozygotes using the $I_{1}$ plants, but because of the limited flowering period of the plants most crosses of this type were made between $\mathrm{I}_{2}$ plants.

The plants raised in the $I_{2}$ generation were the heterozygotes corresponding in genotype to the original $\mathrm{I}_{0}$ plants and one or both of the homozygotes from each $I_{1}$ progeny. Reciprocal crosses between family lines were performed mainly with the heterozygotes (except in the family containing $\mathrm{S}_{9}$ and $\mathrm{S}_{10}$ in which none of the seedling heterozygotes survived) to allow more rapid screening for shared alleles. The homozygotes were used when it was necessary to identify the allele shared by two cross-incompatible heterozygotes, when the activity of an allele was suppressed in the heterozygote, and when a pair of heterozygotes was found to share a known allele and the second allele had to be identified.

\section{RESULTS}

The results are consistent with the existence of a single-locus sporophytic incompatibility system in the population that was investigated. No true self- compatibility was observed, although a few examples of pseudocompatibility were found, and a few incompatible crosses (using the criterion of pollen-tube penetration) set some seed.

Fourteen different S-alleles were found in the ten families that were analysed; four alleles occurred in two and one allele in three of the $\mathrm{I}_{0}$ plants. At the conclusion of the investigation, the alleles were re-numbered consecutively from $S_{1}$ to $S_{14}$. These $\mathrm{S}$-allele numbers will be used subsequently in this paper.

Both dominance and independent action of the $\mathrm{S}$-alleles were found in the heterozygous genotypes. Independent action of alleles was more frequent; in four genotypes, $S_{4} S_{5}, S_{6} S_{7}, S_{8} S_{9}$ and $\mathrm{S}_{12} \mathrm{~S}_{13}$, it occurred in both pollen and stigma; in all the other $I_{0}$ genotypes it occurred in either stigma or pollen. $S_{2}$ was dominant to $S_{1}$ in the stigma, the only example of this kind of interaction that was found. Five alleles showed dominance in the pollen; $S_{4}$ was dominant to $S_{3}, S_{1}$ to $S_{8}, S_{8}$ to $S_{10}, S_{7}$ to $S_{11}$ and $S_{14}$ to $S_{10}$. No allele showed dominance in both pollen and stigma; the recessive allele was always codominant in one or the other.

Only one anomalous result was obtained; two of the five $S_{1} S_{8}$ plants that were tested were fully reciprocally compatible with $\mathrm{S}_{8} \mathrm{~S}_{8}$ homozygotes, instead of showing the expected reciprocal difference caused by $S_{1}$ being dominant to $S_{8}$ in the pollen. But when used as female parents these two plants were cross-incompatible with $\mathrm{S}_{8} \mathrm{~S}_{10}$ heterozygotes, showing that $\mathrm{S}_{8}$ was being expressed in their stigmas. Identical results were obtained when the crosses were repeated.

\section{DISCUSSION}

A single-locus sporophytic system has been reported to control self-incompatibility in all but one of the other members of the Brassicaceae in which the control of self-incompatibility has been investigated. Our results are consistent with the occurrence of a system of this type in Sinapis arvensis, and are further evidence suggesting that selfincompatible crucifers normally have single-locus sporophytic systems. Self-compatible genotypes have been found in several mainly self-incompatible species in the family, but usually in cultivated forms (Sampson, 1964), so their absence from our material is also consistent with previous findings. Further evidence for the absence of self-compatibility from the population that we studied was provided by the strong inbreeding depression shown by the inbred lines, in which weak growth 
and morphological abnormalities of various types were noted in many plants. Similar inbreeding depression has been observed in Brassica oleracea (Ockendon, 1975; Yin, Baggett and Rowe, 1981). Nevertheless, self-compatibility may be advantageous for a colonising weed like $S$. arvensis in some situations and the possibility that selfcompatibility may be found in some populations of the species should not be ruled out.

The greater frequency of dominance in pollen than in the stigma that we have found in this study of $S$. arvensis is based on a very small sample of plants and may not truly reflect the situation in general. Nevertheless, similar results have been reported in a number of close relatives of $S$. arvensis, suggesting that our findings are consistent with a common pattern. Sampson (1964) suggested that it is a characteristic of the genus Raphanus for S-allele dominance to be common in pollen but rare in the stigma; this has been shown to be the case both in the cultivated species $R$. sativus (Tatebe, 1962, Haruta, 1962) and in the weedy $R$. raphanistrum (Sampson, 1964). Thompson and Taylor (1966), in a study of over 120 S-allele heterozygotes of Brassica oleracea var. acephala, found that 42 per cent showed dominance in pollen but only 26 per cent in the stigma. Dominance in the pollen with codominance in the stigma is the most common of the four possible types of allelic interaction reported in Brassica campestris ssp. rapifera (Mackay, 1977). Some less closely related crucifers also show this pattern, for example Lesquerella (Sampson, 1958), but in others, such as Iberis amara (Bateman, 1954), dominance is common in both pollen and stigma.

It is not possible to make an accurate estimate of the number of S-alleles in the $S$. arvensis population that we studied from our data. An approximate estimate can be obtained using the maximum likelihood estimate of Paxman (1963), although this method was introduced for use with one-locus multiallelic gametophytic systems and assumes all alleles to be in equilibrium at approximately equal frequencies. Our data do not meet the requirements of the method because the frequencies of dominant and recessive alleles in a sporophytic system will differ even when the population is in equilibrium. In addition, our sample was not truly random because we excluded families in which fewer than two homozygous classes could be identified. However, in most other respects the ten $I_{0}$ plants used in this analysis can probably be regarded as a more or less random sample of the population. Despite the drawbacks, Paxman's method appears to be the best one that is available. The maximum likelihood estimate is given by the formula

$a_{t}=n\left(1-(1-2 / n)^{m}\right)$

where $a_{t}=$ the total number of alleles found $n=$ the number of alleles in the population $m=$ the number of plants examined.

We found $14 \mathrm{~S}$-alleles in a sample of 10 plants; the estimated total number of S-alleles in the population as a whole, using Paxman's maximum likelihood estimate, is 24 . The true number is almost certainly greater because of inequalities in the frequencies of S-alleles in the population; and any deviation from equality will lead to a reduced probability of sampling some alleles and hence to an underestimate of their total number. The maximum likelihood estimate of $n$ should therefore be regarded as an estimate of the minimum number of $\mathrm{S}$-alleles in the population (Campbell and Lawrence, 1981b). As such, our estimate of 24 S-alleles in Sinapis arvensis corresponds closely with the estimate of 25-34 S-alleles in the closely related and ecologically similar Raphanus raphanistrum made using a different method by Sampson (1967). Sampson's figure refers to the total world population of the species, not to a single local population, but is the only estimate available for a wild crucifer. Among cultivated crucifers, the S-alleles of cole crops (forms of Brassica oleracea s.1.) have been most extensively studied. While very few alleles exist in individual cultivars, totals of about 20 have been found in the Brussels Sprout and Cape Broccoli groups, and totals of just over 30 in the Cabbage and Kale groups (Ockendon, 1982) with at least 50 in the B. oleracea complex as a whole (Ockendon, 1980). It is thus possible that the total number of S-alleles occurring in the world population of $S$. arvensis will prove to be substantially greater than our estimate for a single population.

Acknowledgements $\mathrm{We}$ are grateful to $\mathrm{Mr} \mathrm{R}$. A. Pearce for useful discussion of the work, to Dr A. J. Lack for valuable comments and discussion, and to an anonymous reviewer for suggesting improvements to an earlier draft of the paper. $M$. A. Ford was supported by a research studentship from the SERC during the study.

\section{REFERENCES}

BAteman, A. J. 1954. Self-incompatibility systems in Angiosperms. II. Iberis amara. Heredity, 8, 305-332.

BATEMAN, A. J. 1955. Self-incompatibility systems in Angiosperms. H1. Cruciferae. Heredity, 9, 53-68. 
CAMPBELL, J. M. AND LAWRENCE, M. J. $1981 a$. The population genetics of the self-incompatibility polymorphism in Papaver rhoeas. I. The number and distribution of S-alleles in families from three localities. Heredity, 46, 69-79.

CAMPBELL, J. M. AND LAWRENCE, M. J. $1981 b$. The population genetics of the self-incompatibility polymorphism in Papaver rhoeas. II. The number and frequency of the Salleles in a natural population (R 106). Heredity, 46, 81-90.

EMERSON, S. 1939. A preliminary survey of the Oenothera organensis population. Genetics, 24, 524-537.

FOGG, G. E. 1950. Biological Flora of the British Isles. Sinapis arvensis L. J. Ecol., 38, 415-429.

HARUTA, T. 1962. Studies on the genetics of self- and crossincompatibility in vegetables. Takii Pl. Breed. Exp. Stn. Res. Bull., 2, 1-169.

LLOYD, D. G. 1967. The genetics of self-incompatibility in Leavenworthia crassa Rollins (Cruciferae). Genetica, 38, $227-242$.

MACKAY, G. R. 1977. A diallel cross method for the recognition of S-allele homozygotes in Turnip, Brassica campestris L. ssp. rapifera. Heredity, 38, 201-208.

MUlligan, G. A. AND BAILEY, L. G. 1975. The biology of Canadian weeds. 8. Sinapis arvensis L. Can. J. Plant Sci., $55,171-183$.

OCKENDON, D. J. 1975. The S-allele collection of Brassica oleracea. Incomp. News., 5, 82-84.

OCKENDON, D. J. 1980. Distribution of S-alleles and breeding structure of Cape Broccoli (Brassica oleracea var. italica). Theor. Appl. Genet., 58, 11-15.

OCKENDON, D. J. 1982. An S-allele survey of Cabbage (Brassica oleracea var. capitata). Euphytica, 31, 325-331.
PAXMAN, G. J. 1963. The maximum likelihood estimation of the number of self-sterility alleles in a population. Genetics, 48, 1029- 1032.

SAMPSON, D. R. 1957. The genetics of self- and cross-incompatibility in Brassica oleracea. Genetics, 42, 257-263.

SAMPSON, D. R. 1958. The genetics of self incompatibility in Lesquerella densipila and in the $F_{1}$ hybrid $L$. densipila $\times L$. lescurii. Can. J. Bot., 36, 39-56.

SAMPSON, D. R. 1964. A one-locus self-incompatibility system in Raphanus raphanistrum. Can. J. Genet. Cytol., 6, 435-445.

SAMPSON, D. R. 1967. Frequency and distribution of self-incompatibility alleles in Raphanus raphanistrum. Genetics, 56, 241-251.

TATEBE, T. 1962. Studies on the genetics of self- and crossincompatibility in the Japanese radish. V. J. Jap. Soc. Hort. Sci. 31, 185-192.

THOMPSON, K. F. AND TAYLOR, J. P. 1966. Non-linear dominance relationships between $S$-alleles. Heredity 21, 345-362.

VAN HAL, J. G. AND VERHOEVEN, W. 1968. Identification of S-alleles in brussels sprouts. Proc. Brassica meeting of Eucarpia, Wellesbourne, Sept. 1968, 32-33.

VERMA, S. C., MALIK, R-AND DHIR, I. 1977. Genetics of the incompatibility system in the crucifer Eruca sativa L. Proc. Roy. Soc. B 196, 131-159.

Wallace, D. H. 1979. Procedures for identifying S-allele genotypes of Brassica. Theor. Appl. Genet., 54, 249-265.

YIN, YUN-FU, BAGGETT, J. R. AND ROWE, K. E. 1981. The effects of bud-pollination and open flower self-pollination on the field characteristics of broccoli (Brassica oleracea var. italica). Euphytica, 30, 841-846. 